\title{
A RELAÇÃ̃ ENTRE REVOLUÇ̃̃o E ESTADO: CRÍTICA DE HANNAH ARENDT AO MODELO ATUAL
}

\author{
Carlos Fernando Silva Brito ${ }^{1}$ \\ Universidade Federal de Minas Gerais (UFMG) \\ https://orcid.org/0000-0002-5496-7183 \\ E-mail: semfernand@gmail.com
}

\section{RESUMO:}

Neste texto, pretende-se desenvolver os elementos que compõem a crítica que Hannah Arendt apresenta ao fim da entrevista concedida ao escritor alemão Adelbert Reif no verão de 1970 ao conceito de Estado e governo moderno, e que não são desenvolvidos por Arendt nesse momento. Para tanto, inicialmente será expostas as criticas de Arendt ao esvaziamento do espaço público e a tentativa de resumir à participação política ao processo eleitoral. Para contrapor-se a esses problemas inerentes ao conceito moderno de Estado e governo, Hannah Arendt menciona, mesmo que ligeiramente a possibilidade de um estado-conselho. Entretanto, nesse texto Arendt não explora esses conceitos e experiências, mas apenas os relaciona com a necessidade de transformação do conceito moderno de Estado e governo, ou seja, possibilita a percepção da atualidade de sua reflexão anterior. Diante disso a hipótese explorada neste texto é a de que essa entrevista de 1970 serve de chave de leitura para compreender a pertinência e atualidade do paralelo partidos x conselho desenvolvidos pela autora em Sobre a Revolução em 1963 e acrescenta um elemento novo, a saber, o tema da necessidade de institucionalizar uma experiência esquecida: os conselhos.

PALAVRAS-CHAVE: Conselhos; Estado; Governo; Partidos políticos.

\section{THE RELATIONSHIP BETWEEN REVOLUTION AND STATE: HANNAH ARENDT'S CRITIQUE OF THE CURRENT MODEL}

\begin{abstract}
:
In this text, we intend to develop the elements that make up the criticism that Hannah Arendt presents at the end of the interview granted to the German writer Adelbert Reif in the summer of 1970 to the concept of state and modern government, and that are not developed by Arendt at that moment. To this end, we will initially expose Arendt's criticism of the emptying of public space and the attempt to reduce political participation to the electoral process. To counteract these problems inherent to the modern concept of state and government, Hannah Arendt mentions, even slightly, the possibility of a council-state. However, in this text Arendt does not explore these concepts and experiences, but only relates them to the need for transformation of the modern concept of state and government, i.e., it allows the perception of the actuality of her previous reflection. In view of this, the hypothesis explored in this text is that this 1970 interview serves as a reading key to understand the relevance and actuality of the parallel between parties $x$ council developed by the author in On Revolution in 1963 and adds a new element, namely, the theme of the need to institutionalize a forgotten experience: the councils.
\end{abstract}

KEYWORDS: Councils; State; Government; Political Parties.

\footnotetext{
${ }^{1}$ Doutorando(a) em Filosofia na Universidade Federal de Minas Gerais (UFMG), Belo Horizonte - MG, Brasil.
}

BRITO, Carlos Fernando Silva. A relação entre revolução e Estado: crítica de Hannah Arendt ao modelo atual. Griot : Revista de Filosofia, Amargosa - BA, v.21 n.3, p.121-133, outubro, 2021. 
É tarde mas é nossa hora.

É tarde mas é todo tempo que temos à mão para fazer o futuro.

É tarde mas somos nós esta hora tardia.

É tarde mas é madrugada se insistimos um pouco.

(D. Pedro Casaldáliga)

Este artigo tem como objetivo explorar a breve argumentação de Hannah Arendt de que a revitalização do sentido da política passa pela transformação do conceito de Estado amplamente aceito nas democracias modernas. Para isso, argumenta-se que essa necessidade de transformação que fora explicitamente evocada por Arendt em uma entrevista em 1970 a Adelbert Reif que posteriormente transformara-se no ensaio "Thoughts on Politcs and Revolution: a comentary", apesar de não surgir no pensamento da autora somente no texto de On Revolution (1963) - dado que pode-se ver ecos dessa discussão já no tema da formação do Estado de Israel e em suas críticas ao Estado-nação e sua relação com o totalitarismo -, pode-se afirmar que o tema ganha impulso e novos contornos principalmente na reflexão que Arendt faz em On Revolution sobre a tensão entre o sistema de partidos e os conselhos.

Conforme a autora, essa tensão "[...] ocupou o primeiro plano em todas as revoluções do século XX" (ARENDT, 2011, p. 341). A temática desse embate e suas resultantes torna-se importante para Arendt na medida em que evidencia o fato de que "a questão em jogo era representação versus ação e participação, [...] de um lado, é o conflito entre a rua e o corpo político [...]. De outro lado, é o conflito entre o povo e um aparato de poder impiedosamente centralizado" (ARENDT, 2011, p. 308).

\section{O encolhimento da esfera pública e a vitória dos partidos políticos}

A esfera pública é para Arendt, de modo sintético, o espaço do aparecimento de quem os cidadãos são através da ação e do discurso; lugar da política que revitaliza-se todas as vezes em que o cidadãos vem a público para agir e discursar uns com os outros e uns contra os outros; esfera da liberdade e felicidade pública. Ocorre, entretanto, que em sua obra, Arendt denuncia o que ela chamou de "encolhimento da esfera pública", fenômeno da modernidade que tende a se tornar mais agudo à medida em que o modelo de organização do espaço público é moldado pelos partidos políticos em detrimento de outras formas de participação política, dado que "a cabina de votação dificilmente pode ser vista como um lugar público [...]" (ARENDT, 2018d, p. 213).

Os conflitos entre partidos políticos e os sistemas de conselhos são oriundos das revoluções modernas, especialmente aquela da independência estadunidense de 1775-83 e a francesa de 1789. Em Sobre a revolução (1963), Hannah Arendt observa que os partidos políticos já possuíam a tendência a reduzir a participação e a cidadania ao processo de votação, e isso começa já na fase de elaboração da constituição estadunidense e francesa. Historicamente os partidos levaram a melhor, como veremos a seguir, e para Arendt fora "[...] como se a revolução tivesse dado liberdade ao povo ao mesmo tempo em que lhe negou um espaço no qual pudesse exercê-la, na medida em que fornecia espaço público apenas para os representantes do povo, $\mathrm{e}$ não para o próprio povo" (CORREIA, 2014, p. 201).

Essa disputa entre partidos e conselhos, burocracia e participação intensificou-se na medida em que os conselhos assumiam nas fábricas um papel que não condizia com a sua natureza política. Isso, aos olhos do partido, era perigoso demais para ser tolerado. Como as reivindicações econômicas e sociais possuíam pouca relevância nesses órgãos populares, os partidos viam "[...] esse desinteresse por questões sociais e econômicas [...], [como] um sinal

BRITO, Carlos Fernando Silva. A relação entre revolução e Estado: crítica de Hannah Arendt ao modelo atual. Griot : Revista de Filosofia, Amargosa - BA, v.21 n.3, p.121-133, outubro, 2021. 
seguro da mentalidade "pequeno-burguesa abstrata e liberal' deles" (ARENDT, 2011, p. 342, acréscimo nosso).

A predominância dos partidos em relação aos conselhos ocorre de modo especial pelo fato de que "a atenção deles estava voltada sobretudo para o principal problema imediato, no caso, a questão da representação, e a tal ponto que viera as repúblicas, distinguindo-as das democracias, como governos representativos" (ARENDT, 2011, p. 298). Essa preocupação não chegou à dimensão representativa que existe nos próprios conselhos, assunto do qual trataremos no tópico posterior. Nesse sentido, a síntese do conflito era o fato de que o que os conselhos contestavam "[...] era o sistema partidário em si, em todas as suas formas, e esse conflito se acentuava sempre que os conselhos, nascidos da revolução, se voltavam contra o partido [...]" (ARENDT, 2011, p. 332).

Esse conflito transmite a lição de que “[...] os conselhos são as únicas alternativas democráticas conhecidas ao sistema de partidos, e os princípios sobre os quais eles se baseiam se opõem fortemente aos do sistema partidário em diversos aspectos" (ARENDT, 2018b, p. 81). A divergência existe exatamente porque desde os seus fundamentos até as suas estruturas, essas duas formas de participação na política representam concepções diferentes de política.

Como esclarece a pensadora, “[...] faz parte da própria natureza do sistema partidário substituir a 'fórmula governos do povo pelo povo' por esta fórmula: 'governo do povo por uma elite saída do povo" (ARENDT, 2011, p. 346, grifos da autora). Isto porque o povo é visto apenas como um apoiador das medidas governamentais. A ação não é uma prerrogativa do povo, mas do governo. A dimensão da compreensão da representação nos partidos é aquela que diz respeito à substituição dos agentes políticos e não uma ideia de representação como vínculo entre representante e povo ${ }^{2}$. Explicando esses modos de pensar a representação, Arendt afirma:

\footnotetext{
No primeiro caso [representação como substituição da ação direta do povo], o governo se reduz a mera administração e a esfera pública desaparece [...]; os assuntos políticos são os ditados pela necessidade e que devem ser decididos por especialistas, e não estão abertos a opiniões nem a uma autêntica escolha [...]. No segundo caso [rotatividade da representação através da eleição periódica], um pouco mais próximo da realidade, voltase a afirmar a velha distinção entre governante e governados que a revolução pretendera abolir com o estabelecimento de uma república; aqui mais uma vez o povo não é admitido na esfera pública [...]. O resultado é que o povo ou se afunda na "letargia", precursora da morte da "liberdade pública", ou "preserva o espírito de resistência" a qualquer governo que eleja, visto que o único poder que ele ainda mantem é "o poder de reserva da revolução" (ARENDT, 2011, p. 300, acréscimo nosso).
}

Assim, independente da forma que os partidos escolhem para definirem a representação, ela sempre sacrificará a liberdade política. Se é verdade que "não podemos falar de política quando a liberdade não é compreendida com efetivo engajamento e participação potencial de todo membro da comunidade política nas atividades de governo" (CORREIA, 2014, p. 184), então, enquanto perdurar a hegemonia dos partidos, não falamos de espaço propício para o exercício e existência da política.

Uma das expressões dessa ausência de liberdade na forma de representação da política partidária é a existência dos programas partidários. Para Hannah Arendt, dentre muitos aspectos, "[...] o que mais afastava os conselhos dos partidos eram precisamente os programas

\footnotetext{
2 “[...] toda a questão da representação, um dos problemas mais difíceis e cruciais da política moderna desde as revoluções, na verdade implica uma decisão sobre a própria dignidade da esfera política em si. A alternativa tradicional entre a representação como simples substituta da ação direta do povo e a representação como um domínio popularmente controlado dos representantes do povo sobre o povo constitui um daqueles dilemas que não admitem solução" (ARENDT, 2011, p. 299).
}

BRITO, Carlos Fernando Silva. A relação entre revolução e Estado: crítica de Hannah Arendt ao modelo atual. Griot : Revista de Filosofia, Amargosa - BA, v.21 n.3, p.121-133, outubro, 2021. 
partidários; pois esses programas, por mais revolucionários que fossem, eram todos 'fórmulas prontas' que não requeriam ação, mas apenas execução" (ARENDT, 2011, p. 330). A única dimensão da escolha nesse sistema é aquela que diz respeito à escolha de qual plano partidário o cidadão vai apoiar. "As cabines em que depositamos as cédulas são, sem sombra de dúvida, muito pequenas, pois só tem lugar para um. Os partidos são completamente impróprios; lá somos, quase todos nós, nada mais que o eleitorado manipulado" (ARENDT, 2015, p. 200). Ao contrário dessa realidade, os conselhos são os lugares da expressão livre das opiniões. E através dessa troca de opiniões será possível estabelecer quem é o mais apto para "[...] apresentar nossos pontos de vista diante do conselho" (ARENDT, 2015, p. 200).

Nos partidos, "[...] a tarefa dos associados não era mais discutir e trocar opiniões, propiciar a mútua instrução e partilhar informações sobre os assuntos públicos, mas se espionar uns aos outros e denunciar filiados e não filiados" (ARENDT, 2011, p. 311). Arendt percebe que nesses partidos nem mesmo a questão da representação é uma causa verdadeira, o que nos ajuda a perceber que opor-se aos partidos não significa necessariamente opor-se a políticas de representação. Para demonstrar que o problema apontado por Arendt não está necessariamente alicerçado na questão da representação, José Oliveira faz um resumo de como funcionava esse aspecto orgânico dentro dos sistemas de conselho. Conforme o autor,

\footnotetext{
Os participantes de conselhos, ou de algo de estrutura semelhante, constituíam-se como indivíduos que se apresentavam como uma espécie de elite política do povo. $O$ ponto de partida para a ação dessa elite política encontrava-se no fato de essas organizações escolherem seus representantes para o conselho imediatamente superior. Os representantes escolhidos eram selecionados por seus pares, sem pressões superiores ou inferiores. A posição desses participantes escolhidos era respaldada tão somente pela confiança de seus iguais. Não se constituía uma igualdade natural, mas política, diferentemente de a terem possuído por direito de nascença. $O$ que caracterizava essa igualdade era o fato de ela ser o sinal do comprometimento com a empresa conjunta, na qual todos se encontravam engajados. No momento em que uma pessoa era eleita e, consequentemente, enviada a um conselho superior imediato, esta pessoa, como representante, se encontrava novamente entre os seus pares. $O$ escolhido apresentava-se diante de outras pessoas que, como ele, deveriam falar em nome daqueles que o elegeram no âmbito das organizações elementares. Configurava-se um sistema em que todos os escolhidos para o conselho superior haviam recebido um voto especial de confiança (OLIVEIRA, 2009, p. 276).
}

Assim, Oliveira sintetiza o fato de que Arendt indica que mesmo no sistema de conselhos haveria uma espécie de eleição que indicaria membros entre seus pares para a representação em um conselho superior. "A diferença, porém, consiste em que os eleitos pelo sistema de conselhos não eram indicados de cima, mas escolhidos pelos seus pares" (RUBIANO, 2016, p. 229-230) e, por isso mesmo, em vez de representarem alguém de dignidade assimétrica à sua, como no caso dos partidos, os eleitos pelos conselhos possuem o mesmo grau de comprometimento daqueles que os elegeram, isto porque os eleitos permanecem parte do conselho elementar que os escolheu.

Outro aspecto apresentado é o da existência de uma elite política. De modo diverso aos partidos, a elite dos conselhos é escolhida segundo a condição de igualdade onde todos podem, eleitores e eleitos, exercer sua liberdade, tendo em vista que se apresentam no espaço público primeiro como agentes iguais e não como candidatos à ação. Essa espécie de elitismo provém do fato de que em nenhum lugar haveria um espaço público tão amplo que pudesse abranger a todos os cidadãos. Por isso, os conselhos são espaços da entrada espontânea, de tal forma que os não desejam participar dos assuntos públicos não são forçados a fazê-lo. Essa elite se distribuiria

BRITO, Carlos Fernando Silva. A relação entre revolução e Estado: crítica de Hannah Arendt ao modelo atual. Griot : Revista de Filosofia, Amargosa - BA, v.21 n.3, p.121-133, outubro, 2021. 
pelas fileiras das mais diversas instâncias federativas, sempre através da autoescolha (DUARTE, 2000, p. 312).

Assim, se evitaria o fato de que as opiniões populares fossem reduzidas a meras demandas pelo bem-estar da vida privada dos cidadãos. Ao contrário dos partidos, lugar onde "[...] é realmente impossível auscultar as opiniões do povo, pela simples razão de não existirem" (ARENDT, 2011, p. 336), nos conselhos, a representação passa primeiro pelo elemento da deliberação que só ocorre mediante a troca de opiniões.

Outro aspecto que torna os conselhos relevantes para Arendt é que se pensarmos de modo regresso eles serviriam de antídotos para as estruturas propícias para o surgimento do totalitarismo. Conforme Rodrigo Alves Neto, os movimentos totalitários surgidos na modernidade demonstram quão danosos podem ser os efeitos de um sistema democrático onde a maioria dos homens não possui espaço de acesso para participar dos assuntos públicos (ALVES NETO, 2013, p. 57). André Duarte reforça essa tese ao afirmar que para Arendt "[...] os conselhos seriam a melhor forma de 'fragmentar' e politizar as grandes 'massas' que povoam as sociedades modernas, impedindo que fossem arregimentadas e organizadas pelos partidos políticos demagógicos em movimentos de massa "pseudopolíticos"” (DUARTE, 2000, p. 313), como foram os movimentos nazista e stalinista.

Apesar desses inúmeros defeitos, o sistema partidário conseguiu levar vantagem em relação aos conselhos. Segundo Arendt, isto " $[. .$.$] residia exatamente na sua estrutura original$ oligárquica e até autocrática, a mesma que os fazia tão absolutamente inconfiáveis para todos os fins políticos" (ARENDT, 2011, p. 343). Por possuírem uma estrutura que dependia de menor número de atores, o consenso era alcançado mais rápido e a execução se colocava em marcha de modo mais seguro, porque era controlada por um número mínimo de pessoas. Assim os conselhos morreram exatamente quando a felicidade fora confundida com um bem privado ${ }^{3}$ que necessitava de urgência para ser alcançado, sendo preferidas estruturas menos políticas, porém, de poder de reação mais rápido ${ }^{4}$.

De acordo com Arendt, o sucesso do sistema partidário também se explica pelo fato de que um conceito de Estado foi moldado e o resultado desse conceito fora a escolha de estruturas partidárias em vez de populares. Nas palavras de Adriano Correia,

Para Arendt, são várias as razões para que os sistemas de conselhos, que desempenharam papel decisivo nas revoluções, não tenham ainda se convertido em uma nova forma de governo consolidada: o falso antagonismo entre representação e participação; o eventual conflito dos conselhos com a busca por estabilidade; a obsessão com a questão social e o correspondente descuido com questões de Estado e governo; a aberta contestação do sistema partidário; a interpretação da felicidade pública em termos de bem-estar privado ou social (CORREIA, 2014, p. 203).

Esses elementos elencados pelo autor foram explorados neste tópico, entretanto, achamos prudente dedicar um momento especial para a reflexão sobre o que Adriano Correia classificou como "o correspondente descuido com questões de Estado e governo". Arendt tece fortes críticas

\footnotetext{
${ }^{3}$ “`A liberdade do povo está em sua vida privada; não a perturbem. Que o governo [...] não seja uma força senão para proteger esse estado de simplicidade contra a própria força'. Na verdade, essas palavras decretam a sentença de morte para todos os órgãos populares e decretam com uma rara clareza o fim de todas as esperanças para a revolução" (ARENDT, 2011, p. 307).

4 "Foram esmagados pelo governo central e centralizado, não porque representassem uma verdadeira ameaça a ele, mas porque de fato, em virtude de sua própria existência, eram rivais concorrendo ao poder público [...]. Um fato bastante interessante é que, entre todos os pontos de atrito entre as sociedades populares e o governo, o único que acabou se demonstrando decisivo foi o caráter apartidário delas. Os partidos, ou melhor, as facções, que tiveram um papel tão calamitoso na Revolução Francesa e depois se tornaram as raízes de todo o sistema partidário continental, nasceram na Assembleia [...]” (ARENDT, 2011, p. 310).
}

BRITO, Carlos Fernando Silva. A relação entre revolução e Estado: crítica de Hannah Arendt ao modelo atual. Griot : Revista de Filosofia, Amargosa - BA, v.21 n.3, p.121-133, outubro, 2021. 
ao conceito de Estado enquanto nação, de modo especial quando a autora se debruça sobre a questão do totalitarismo e do Estado judaico. Na abordagem dos conselhos não é diferente, a problemática do conceito de Estado mais uma vez é pertinente.

Conforme Arendt, um dos motivos do sucesso dos partidos é o "[...] surgimento do Estado Nacional [...]" (ARENDT, 2011, p. 311). Sem distinguir partidos de esquerdas de partidos de direita, a autora acredita que nos dois espectros os conselhos são vistos como uma ameaça, e comprova isso quando fala da força repressora do governo de Lênin aos conselhos húngaros (ARENDT, 2011, p. 323) e do episódio nazista de dominação totalitária. Isso nos parece suficiente para argumentarmos que a compreensão do status do sentido da política na modernidade passa pela compreensão do conceito de Estado que surge da experiência revolucionária. Assim, no tópico seguinte examinaremos a realidade dos conselhos como uma nova possibilidade de conceitualizar o Estado, possibilidade intimamente ligada com a tarefa de ressignificação do sentido da política na modernidade.

\section{Por uma república de conselhos?}

A pergunta pela existência ou não de um conceito de Estado no pensamento de Arendt já foi preocupação de muitos dos seus comentadores. Conforme mostraremos aqui, há uma diversidade de interpretações em relação a essa questão de uma possível república dos conselhos no pensamento de Arendt. Que há a necessidade de superação do conceito de Estado-nação isso é consenso entre os mais diversos leitores, conforme apresentaremos; contudo, a problemática reside exatamente em saber qual outra forma de governo seria responsável pelo processo de superação.

Dentre as obras de Arendt, não há nenhuma que possa ser classificada como um esforço de Arendt para a criação de uma teoria das formas de governo. Todavia, ao longo de todos os seus textos, a menção a formas "caducas" é sempre recorrente, e Arendt sempre alude para a necessidade de superação das mesmas. No que diz respeito à revolução, a pensadora, "[...] nunca realmente se dedica a mostrar como se daria a combinação entre estabilidade e mudança, nem como o momento inicial pode se estender no tempo, ou se repetir, de modo a formar um espaço público permanentemente aberto" (DRUCKER, 2001, p. 211). Uma chave de leitura desse problema é a relação de Arendt com a tradição republicana.

[...] existe em Hannah Arendt uma filosofia política que não só guarda laços com a tradição republicana, mas que inova ao propor um novo republicanismo, que não só está em sintonia com as muitas transformações ocorridas no último século, mas que encontra na ação de homens e mulheres um caminho para recuperar a dignidade da política (SILVA, 2016, p. 222).

É exatamente por fazer parte do caminho da recuperação da dignidade da política que a questão da forma de governo substituta do Estado-nação já corroído é crucial ${ }^{5}$. A pergunta sobre "[...] como continuar o que inicia se a ação que começa e rompe a continuidade histórica não é uma ação que continua e se a continuação que tenta prolongar o começo é simultaneamente uma ordem de efetivação (continuidade) e de realização (autoridade)?" (TASSIN, 2016, p. 119), pode ser traduzida nos seguintes termos: qual estrutura política conteria um espaço próprio para o agir revolucionário que tende a sempre instaurar o novo?

\footnotetext{
5 "Mas como continuar o que assim inicia? Quais instituições, nascidas da revolução, seriam capazes de perseguir seu desígnio sem trair seu espírito? Se, como diz Arendt, a ação revolucionária é na modernidade a ação política por excelência, compreender esta aporia é compreender a própria política" (TASSIN, 2016, p. 112).
}

BRITO, Carlos Fernando Silva. A relação entre revolução e Estado: crítica de Hannah Arendt ao modelo atual. Griot : Revista de Filosofia, Amargosa - BA, v.21 n.3, p.121-133, outubro, 2021. 
Para alguns, a sutileza desses problemas apresentados consiste em uma fragilidade do pensamento de Hannah Arendt. No entanto, acreditamos como André Duarte que "aquilo que alguns intérpretes tendem a conceber como uma ambiguidade ou uma incoerência da reflexão política arendtiana tem de ser visto, na verdade, como um sinal de sua riqueza e originalidade" (DUARTE, 2000, p. 234), isto porque após o solapamento das seguranças teóricas que a tradição legara, Arendt fulgura como uma pensadora que busca compreender seu tempo a fim de pensar a restituição do sentido da política.

Apresentado de modo sintético a pertinência desse problema para a nossa pesquisa, seguiremos com a apresentação das interpretações sobre o significado dos sistemas de conselho para o pensamento de Arendt. Nesse processo de compreensão, um equívoco muito difundido é o de se pensar essas estruturas revolucionarias apenas como metáforas. Tal equívoco parece ter raízes nas interpretações de $\mathrm{Wellmer}^{6}$. Para este autor, os conselhos são uma metáfora usada por Arendt para descrever uma rede de instituições autônomas nas quais acontece o autogoverno dos membros de cada instituição.

Mariana Rubiano se opõe a essa interpretação errônea, destacando dois equívocos da interpretação de Wellmer. Segundo esta autora, o comentador negligencia "[...] a relação entre libertação, direitos civis e liberdade e a indicação de que há tanto espaços públicos espontâneos quanto institucionalizados" (RUBIANO, 2016, p. 26). Conforme percebemos nos tópicos expostos anteriormente, Arendt tece uma longa reflexão sobre a fundação de estruturas duráveis e que dizem respeito à forma de toda a sociedade se relacionar com a liberdade e os direitos civis. Se tomada a interpretação de Wellmer como verdadeira, corre-se o risco de reduzir os conselhos a um tipo de organização dentro do corpo social, sendo possível a coexistência dessa forma ao lado de outras como as dos partidos, o que se apresenta como inviável, dado o conflito que já fora exposto estre essas duas estruturas.

Outra interpretação possível, mas que também não nos parece totalmente adequada, é apresentada por Rodrigo Alves Neto. Nas palavras do autor:

Não há, na obra arendtiana, uma resposta simples, imediata e acabada para essas indagações cruciais. Não há, como nas ciências políticas, uma descrição positiva de exemplos concretos de ordenamentos políticos. Não há, como nas filosofias políticas tradicionais, a formulação de um modelo ideal normativo e fechado, nem mesmo de origem greco-romana, a ser implantado ou a partir do qual poderíamos avaliar a situação da política no presente (ALVES NETO, 2013, p. 56).

O comentador é feliz ao afirmar que não há uma resposta simples para a questão das formas de governo no interior do pensamento da autora, e também quando afirma que para Arendt o modelo de origem greco-romano não deve nem pode ser implantado na modernidade. Entretanto, nos parece estática demais a afirmação de que não encontramos no pensamento da autora uma descrição de exemplos concretos de ordenamentos políticos, isto porque inúmeras vezes Arendt se debruça sobre formas de governo ao longo de sua obra, mesmo que não seja para prescrever alguma delas como modelo. Porém, quando se trata dos sistemas de conselho, parece haver maior sensibilidade e esperança de Arendt em relação a essa forma de organização do campo dos assuntos humanos.

\footnotetext{
6 "As instituições políticas de sociedades modernas complexas dificilmente podem ser construídas do zero no modelo simples de um sistema de conselhos. Portanto, considero a sua ideia do sistema de conselhos uma metáfora para uma rede de instituições, organizações e associações autônomas ou parcialmente autônomas, em cada uma das quais ocorre algo como o autogoverno de participantes livres e iguais - em cada caso, de maneiras diferentes, com objetivos diferentes e com meios diferentes para recrutar novos membros: uma rede cujas unidades podem estar conectadas horizontal e verticalmente, relacionadas uma com as outras ou dependentes umas das outras" (WELLMER, 2001, p. 224).
}

BRITO, Carlos Fernando Silva. A relação entre revolução e Estado: crítica de Hannah Arendt ao modelo atual. Griot : Revista de Filosofia, Amargosa - BA, v.21 n.3, p.121-133, outubro, 2021. 
Por conseguinte, acreditamos que a melhor descrição do significado dos sistemas de conselho no pensamento de Arendt possa ter sido oferecida primeiro por Adriano Correia, que afirma que "um Estado-conselho, tal como ela o imagina, é muito menos que um modelo, mas possivelmente algo mais que uma metáfora" (CORREIA, 2014, p. 208) e, posteriormente, por Mariana Rubiano, ao asseverar que "[...] o sistema de conselhos consiste em uma forma alternativa de organização do Estado que surgiu em vários levantes revolucionários" (RUBIANO, 2016, p. 242). Por nossa vez, acreditamos que os conselhos não são um modelo prescrito por Arendt, mas são, dentro das inúmeras formas de governo já conhecidas pela tradição ocidental, a única que para a pensadora pode servir como alternativa para o conceito atual de Estado-nação, a única onde o sentido da política pudesse ser reestabelecido.

Essas reflexões são respostas à questão sobre qual seria a forma de organização do corpo político que permite cumprir da melhor maneira as duas tarefas da revolução: a fundação da liberdade e a preservação do espírito público (AMIEL, 1996, p. 99). Os conselhos seriam, portanto, uma forma na qual o sentido da política fosse reeditado conforme o seu sentido original inspirado nos gregos e romanos antigos. Alinhando ainda mais a função dos conselhos no pensamento de Arendt, menos como modelo e mais como uma alternativa possível, a pensadora afirma que o que ela tem em mente "[...] não é tanto um conceito diferente de estado, mas a necessidade de mudar este. O que chamamos 'estado' não é muito mais velho que os séculos quinze e dezesseis, e o mesmo se passa com o conceito de soberania" (ARENDT, 2015, p. 198).

Estas considerações auxiliam no entendimento de que estas reflexões de Arendt não visam a prescrição de um modelo teórico, mas sim o exame das possibilidades de transformação da política moderna a fim de favorecer uma ressignificação da dignidade e do sentido da política. Esse processo de transformação passa pela mudança na compreensão daquilo que seria o governo. Para Arendt, "[...] o governo é essencialmente poder organizado e institucionalizado, a questão ordinária ‘qual é o fim do governo?' também não faz muito sentido. A resposta será redundante [...] ou perigosamente utópica" (ARENDT, 2016c, p. 69). Redundante porque se o governo é poder organizado e o poder surge da ação conjunta dos homens, então descrever a finalidade do governo como sendo a arte de possibilitar a convivência seria dar voltas no mesmo eixo. Utópica seria a resposta de que o governo visa promover a felicidade ou concretizar a sociedade sem classes ou qualquer outro ideal não político. Na sede desse conceito de governo se encontra as noções de "pacto mútuo".

Arendt distingue entre dois tipos de pactos/contratos políticos, mais especificamente, um vertical e outro horizontal. No vertical, "[...] o consentimento que legitima o poder constituído requer a abdicação de poder por parte daqueles que o constituíram [...]" (DUARTE, 2000, p. 252). Na versão horizontal do contrato "[...] esse consentimento está na própria base de constituição de um poder que se mantem na posse do contratante" (DUARTE, 2000, p. 252). Esses modos de contrato expressam duas compreensões sobre o poder que consequentemente alinham duas formas de organização do corpo político. No caso horizontal, o poder "[...] pode ser entendido como algo que surge da associação entre os homens e se sustenta na participação nos assuntos públicos [...]" (RUBIANO, 2016, p. 214), o que só é possível no Estado-conselho. No modelo vertical, "[...] o poder pode ser entendido como dominação, seu fundamento está na divisão entre aqueles que ordenam e aqueles que obedecem e executam ordens" (RUBIANO, 2016, p. 214), o que já é experimentado na versão do Estado-nação onde quem governa pode ordenar e quem é governado deve obedecer. Sobre essa pluralidade de formas, Heuer afirma: 
A forma do estado e da política tem que ser definida pela pluralidade, que, para Arendt, é a base antropológica da existência humana. [...] A política horizontal possibilita o nascimento do poder, enquanto a política vertical reduz o poder em favor da violência. Para Arendt, não se pode pensar sobre a república e as instituições sem pensar sobre a república decisiva: que é a política e como se atua quando crê atuar politicamente (HEUER, 2009, p. 47).

Essa característica do governo como horizontal é para Arendt a única forma possível de se pensar uma transformação do conceito de Estado. Desde as reflexões sobre a questão judaica, Arendt já via o Estado-nação como modelo incapaz de abrigar em seu corpo político a pluralidade $^{7}$. E especificamente, no caso dos judeus e do território de Israel, a ideia de um Estado pautado num contrato vertical, para Arendt, conduziria (cedo ou tarde) a uma guerra civil. Isto porque esse modelo é incapaz de associar em si o fenômeno da pluralidade. A Nação "[...] é uma categoria natural, que prescinde de laços públicos e afirma a homogeneidade de uma comunidade baseada em um nascimento comum. Na medida em que a comunidade deixa de ser vista em sua pluralidade e é entendida como homogênea" (RUBIANO, 2016, p. 249).

Mais especificamente, o Estado-conselho poderia ser descrito também como Estadofederado. Arendt afirma que os únicos fundamentos que ela vê para um novo conceito de Estado estão presentes no sistema federalista. Nesse sistema, a "[...] vantagem é que o poder não vem nem de cima nem de baixo, mas é dirigido horizontalmente de modo que as unidades federadas refreiam e controlam mutuamente seus poderes" (ARENDT, 2015, p. 198). Falando sobre esse Estado-federado no caso dos judeus, a nossa pensadora esclarece:

A proposta alternativa de um Estado federado, também endossada recentemente pelo Dr. Magnes, é muito mais realista; a despeito do fato de que estabelece um governo comum para dois povos diferentes, ela evita a conformação problemática da maioriaminoria, que é insolúvel por definição. Uma estrutura federada, ademais, teria de se basear em conselhos comunitários judaico-árabes, o que significaria que o conflito judaico-árabe seria resolvido no nível mais baixo e promissor de proximidade e vizinhança. Um Estado federado, finalmente, poderia ser o trampolim natural para a constituição futura de qualquer estrutura federativa mais ampla na área do Oriente Médio e do Mediterrâneo (ARENDT, 2016e, p. 668-669).

A opção de Arendt por um Estado-federado ${ }^{8}$ se dá em grande medida pelo fato de que essa forma de organização evita macroestruturas independentes. Podemos dizer que a dimensão federada encarna nas instituições o princípio político da pluralidade. No interior dessa organização, "as sociedades populares sugeriam a possibilidade de um poder não centralizado e divisível, exercido pela própria população de maneira federativa [...]" (DUARTE, 2000, p. 302). A federação seria a única onde se poderia "[...] manter vivo, sob uma forma institucional apropriada, o poder dos começos: ela requer uma instituição que, durável, preserve dentro de si não as conquistas da revolução, mas seu princípio, o espirito dos começos [...]" (TASSIN, 2016, p. 120).

\footnotetext{
7 "Uma outra questão a ser colocada aos sionistas diz respeito à organização nacional. Temos acompanhado o declínio catastrófico do sistema do Estado nacional em nosso tempo. [...] é que o Estado nacional não é capaz de proteger a existência de uma nação, sequer capaz de garantir a soberania do povo. [...] os países orientais deram os melhores exemplos possíveis de que o Estado nacional não pode existir com uma população misturada" (ARENDT, 2016d, p. 630).

${ }^{8}$ Judith Butler de certa forma percebe nas reflexões de Arendt sobre o Estado-federado proposto para o povo judeu de Israel, uma forte presença do zelo pela pluralidade, de modo que se a política é expressão da pluralidade, as formas de governos devem expressar esse aspecto da política. Essa noção de pluralidade será de grande valia para a filósofa Judith Butler pensar a realidade das manifestações da política em nível não-governamental (BUTLER, 2018, p. 126).
} 
Contudo, Arendt acredita que essas reflexões sobre a possibilidade de uma nova forma de organização do corpo político se perderam. Para a autora, "a falha no pensamento pósrevolucionário em lembrar o espírito revolucionário e entendê-lo conceitualmente foi precedida pela falha da revolução em lhe fornecer uma instituição duradoura" (ARENDT, 2011, p. 293294). Com a perda dessa possibilidade de transformação da forma de organização do corpo político, perdeu-se também a esperanças daqueles que acreditavam poder se tornarem participantes nos assuntos públicos (ARENDT, 2011, p. 331).

Arendt fala de esperança que fora sepultada, porque mesmo num processo acelerado de derrocada dessas estruturas populares nas revoluções, havia quem acreditasse ser possível a conciliação do elemento revolucionário com a estabilidade da fundação, como se deu no exemplo de Thomas Jefferson. "Ele esperava que os distritos permitissem aos cidadãos continuar a fazer o que tinham sido capazes de fazer durante os anos da revolução, isto é, agir por iniciativa própria e participar nos assuntos públicos, conforme eram encaminhados dia a dia" (ARENDT, 2011, p. 215). Para Arendt, se "tivesse sido implantado o plano das 'repúblicas elementares' de Jefferson, ele teria superado em muito os frágeis germes de uma nova forma de governo que podemos discernir nas seções da Comuna de Paris e nas sociedades populares [...]" (ARENDT, 2011, p. 313).

Apenas para encerrar a abordagem dessa reflexão de Arendt sobre esse possível novo Estado, destacamos a não ingenuidade da pensadora que compreende ser essa uma realidade um tanto quanto improvável nas condições atuais do mundo moderno, porém, não impossível. Sobre a crença nessa possibilidade, ou não, Arendt afirma:

Um estado-conselho deste tipo, para o qual o princípio de soberania fosse totalmente discrepante, seria admiravelmente ajustado às mais diversas espécies de federações, especialmente porque nele o poder seria constituído horizontalmente e não verticalmente. Mas se você me perguntar que probabilidade existe de ele ser realizado, então devo dizer: Muito pouca, se tanto. E ainda, quem sabe, apesar de tudo - no encalço da próxima revolução (ARENDT, 2015, p. 201).

Arendt é consciente de que é muito pouco provável que esse Estado-conselho venha a se tornar uma realidade, pois muitas das estruturas negativas já se cristalizaram e se plasmaram, conforme o evento do totalitarismo tornou explícito. Entretanto, como saldo fica o fato de que suas observações acerca da forma de governo adequada para as funções da revolução a encaminham e a aproximam da tradição de pensamento republicana. Conforme José Oliveira, em Arendt,

\footnotetext{
Trata-se de um republicanismo alicerçado em experiências modernas de espaços públicos. Tais experiências, mesmo na atualidade, seriam instrumentos de estrutura organizacional configurados em conselhos assinalados por Arendt ou estruturas semelhantes a eles como as sociétés populares francesas e o modelo dos autogovernos da América do Norte. Nesses espaços, a liberdade política não era um desejo, mas tratavase de experiência vivenciada capaz de garantir um republicanismo caracterizado pela participação direta daqueles que quisessem se dispor em atos e palavras, e não serem apenas representados por grupos seletos estabelecidos somente pela via do voto expresso na urna em um único dia de atividade eleitoral (OLIVEIRA, 2016, p. 83-84).
}

Se essa experiência dos conselhos tivesse ganhado forma institucional como Arendt acreditava ser possível, "[...] poderia constituir[-se] a solução para um dos problemas mais sérios de toda a política moderna, que não é como reconciliar liberdade e igualdade, e sim como reconciliar igualdade e autoridade" (ARENDT, 2011, p. 348). E isto só seria possível graças à 
retomada da importância dos momentos iniciais da fundação para a preservação do sentido da política. "Com isso, Arendt renovou o pensamento republicano. [...] Com ela o republicanismo ganha um lugar de destaque entre as matrizes teóricas mais fecundas para se pensar o mundo contemporâneo" (BIGNOTTO, 2011, p. 57).

Uma outra consequência teórica dessa abordagem de Arendt é aquela que diz respeito às acusações de que seu pensamento estaria demasiadamente apegado a uma nostalgia para com os gregos. $\mathrm{O}$ acento dado a uma realidade puramente moderna como exemplificação de sua reflexão sobre a política como modo de vida pautado na liberdade e na igualdade, afasta toda e qualquer possível interpretação de apego ao passado a uma tradição (AIMEL, 1996, p. 130-131). "Como todo bom pensamento republicano, para Arendt, estes momentos de fundação são apenas exemplos históricos de grandes homens de grandes feitos. Arendt sabe muito bem que o passado não é recuperável [...]" (EISENBERG, 2001, p. 173).

Destarte, com as exposições acima, percebemos que Arendt apresenta uma outra tradição possível para se pensar o sentido da política e as manifestações desse sentido na modernidade. "A outra tradição de Arendt nos mostra que o caminho para uma república forte consiste na substituição da violência pelo poder - um conhecimento que parece fácil, mas que está difícil de realizar" (HEUER, 2009, p. 63). Certamente, um dos principais elementos que acompanha a reflexão de Arendt desde o seu diálogo com os antigos até aqui na reflexão sobre as formas de governo é a pluralidade. Especialmente neste último momento, a pluralidade aparece "[...] tanto pela recusa de um modelo único do 'bom regime', como pela recusa do primaz exclusivo de uma faculdade humana" (AMIEL, 1996, p. 11). Dizendo de outra forma, “[...] a ação liga-se à pluralidade em dois aspectos, a saber, envolve um conjunto de pessoas singulares e não tem uma única forma de ser realizada" (RUBIANO, 2016, p. 138).

Essas afirmações de Anne Amiel e Mariana Rubiano são importantes porque mostram como os conceitos que surgem para Arendt, na medida em que ela se depara com a busca pelo sentido da política, pautam todo o percurso teórico de sua obra. Com um percurso marcado pela dedicação em "[...] pensar aqueles instantes extraordinários em que a prática política é reapropriada pelos cidadãos e usurpada ao Estado e aos partidos políticos, transformando-se em evento revolucionário e criativo" (DUARTE, 2000, p. 316-317). Como pensadora de fenômenos ímpares, não se deve exigir de seu pensamento soluções prontas e definitivas. Consciente disso, não pretendíamos esgotar a reflexão sobre uma possível compreensão do Estado no pensamento de Arendt, mas apenas lançar luz sobre um aspecto que as vezes é negligenciado por algumas interpretações. Para nós, a compreensão do apelo arendtiano pela renovação do conceito de Estado passa pela assimilação das categorias que gravitam entorno da questão do sentido da política. 


\section{Referências}

ALVES NETO, Rodrigo Ribeiro. A crítica arendtiana à democracia liberal e o sentido político da liberdade. Cadernos de Ética e Filosofia Política, n. 23, 2013, p. 52-63.

AMIEL, Anne. Hannah Arendt, política e acontecimento. Trad. Sofia Mota. Lisboa: Instituto Piaget, 1996.

ARENDT, Hannah. Sobre a Revolução. Trad. Denise Bottmann. São Paulo: Companhia das Letras, 2011.

ARENDT, Hannah. Reflexões sobre a política e revolução: um comentário. In: ARENDT, Hannah. Crises da República. Trad. José Volkmann. 3. ed. São Paulo: Perspectiva, 2015, p. 171201.

ARENDT, Hannah. Sobre a Violência. Trad. André de Macedo Duarte. 7. ed. Rio de Janeiro: Civilização Brasileira, 2016c.

ARENDT, Hannah. O judeu como pária: uma tradição oculta. In: ARENDT, Hannah. Escritos Judaicos. Trad. Lauraa Mascaro, Luciana Garcia, Thiago da Silva. Barueri: Amarilys, 2016d, p. 493-523.

ARENDT, Hannah. Para salvar a pátria judaica. In: ARENDT, Hannah. Escritos Judaicos. Trad. Lauraa Mascaro, Luciana Garcia, Thiago da Silva. Barueri: Amarilys, 2016e, p. 653- 670. ARENDT, Hannah. Imperialismo totalitário: reflexões sobre a revolução húngara. In: ARENDT, Hannah. Ação e a busca da felicidade. Org. Heloisa Starling; Trad. Virginia Starling. 2. ed. Rio de Janeiro: Bazar do tempo, 2018b, p. 21-112.

ARENDT, Hannah. Direitos públicos e interesses privados: uma resposta a Charles Frankel. In: ARENDT, Hannah. Ação e a busca da felicidade. Org. Heloisa Starling; Trad. Virginia Starling. 2. ed. Rio de Janeiro: Bazar do tempo, 2018d, p. 209-224

BIGNOTTO, Newton. Hannah Arendt e a revolução francesa. O que nos faz pensar, v. 20, n. 29, 2011, p. 41-58.

BUTLER, Judith. Corpos em aliança e a política das ruas: notas para uma teoria performativa da assembleia. Trad. Fernanda Siqueira Miguens. 1. ed. Rio de Janeiro: Civilização Brasileira, 2018. CORREIA, Adriano. Hannah Arendt e a modernidade: política, economia e a disputa por uma fronteira. Rio de Janeiro: Forense Universitária, 2014.

DRUCKER, Claudia. O destino da tradição revolucionaria: auto-incompreensão ou impossibilidade ontológica? In: BIGNOTTO, Newton; MORAES, Eduardo Jardim (Orgs.). Hannah Arendt: diálogos, reflexões e memórias. Belo Horizonte: UFMG, 2001, p. 196-214.

DUARTE, André. O pensamento à sobra da ruptura: política e filosofia em Hannah Arendt. São Paulo: Paz e Terra, 2000.

EISENBERG, José. Comunidade ou República? Hannah Arendt e as linguagens do pensamento político contemporâneo. In: BIGNOTTO, Newton; MORAES, Eduardo Jardim (Orgs.). Hannah Arendt: diálogos, reflexões e memórias. Belo Horizonte: UFMG, 2001, p. 166-175. HEUER, Wolfgang. Debilidades da república hoje. In: VAZ, Celso; Winckler, Silvana (Orgs.). Uma obra no mundo: diálogos com Hannah Arendt. Chapecó: Argos, 2009, p. 41-66.

OLIVEIRA, José. Liberdade política e representação: elementos para a compreensão do republicanismo de Hannah Arendt. Cadernos de Ética e Filosofia Política, v. 1, n. 28, 2016, p. 7185.

OLIVEIRA, José. A estrutura de organização do corpo político na concepção de Hannah Arendt. Revista de Filosofia Unisinos, v. 3, n. 10, 2009, p. 265-277. 
RUBIANO, Mariana de Matos. Revolução em Hannah Arendt: compreensão e história. Tese (Doutorado em Filosofia) - Faculdade de Filosofia, Letras e Ciências Humanas da USP. São Paulo, 2016.

SILVA, Elivanda Oliveira. Da Ruptura com a Tradição à Primazia da Ação Política: Arendt, Pensadora Republicana? In: CONCEIÇÃO, Edilene M.; OLIVEIRA, Elivanda; PASSOS, Fábio A.; OLIVEIRA, José Luiz (Org.). Hannah Arendt; Pensamento, Revolução e Poder. ed. 1. Rio de Janeiro: Lumen Juris, 2016, p. 219-226.

TASSIN, Etienne. Como continuar o que inicia: a tripla aporia revolucionária. Cadernos de Filosofia Alemã: Crítica e Modernidade, v. 21, n. 3, 2016, p. 111-122.

WEILL, Simone. Sobre a supressão geral dos partidos. Trad. Teixeira Coelho. São Paulo: Iluminuras, 2018

WELLMER, Albrecht. Arendt on revolution. In: VILLA, Dana (Org.) The Cambridge Companion to Hannah Arendt. Cambridge University Press, 2001. p. 220-241.

Autor(a) para correspondência / Corresponding author: Carlos Fernando Silva Brito. semfernand@gmail.com 